\title{
THE DIFFICULTY CAUSED BY THE FRAGILITY OF THE OVA OF ASCARIS LUMBRICOIDES
}

\author{
BY
}

\author{
K. B. ROGERS \\ From the Children's Hospital; Birmingham
}

(RECEIVED FOR PUBLICATION APRIL 17, 1952)

The standard textbooks of clinical pathology and of laboratory technique describe the typical ova of Ascaris lumbricoides as being easily recognized, but all refer to the difficulty in recognizing certain of the ova. The following observation may explain why it is sometimes so difficult to recognize them.

When searching for these ova it is convenient to work with relatively thick faecal emulsions and to make a preliminary search with a low power, a 1 in. or $\times 4$ objective, because of their very typical appearance and relatively large size and colour. If an ovum is seen it can be centred and examined with a $2 / 3$ or $1 / 6$ objective to confirm its identity. Todd and Sanford's (1948) description of the typical fertilized ova is that

" they are elliptic, measuring 45 to 60 by 60 to 75 microns, are yellow to brown in colour, and have an unsegmented protoplasm. There is usually a crescentic clear space at each pole, between the contents and the sheli. The shell is moderately thick and smooth, and is covered with an irregular albuminous coating."

No mention is made here, or in any other book I have seen, of the ease with which the ova are broken and distorted. All ascaris ova appear to be equally fragile.

When making a routine examination of a faecal emulsion from a case known to harbour adult ascaris worms no ova could be found in several slides, and a drop of the faecal emulsion was then examined on a slide without a cover slip being placed over it. Several typical ova were then easily found, but what is now recognized to be an automatic, stereotyped, but at that time unconscious movement was observed when a cover slip was placed over this drop. The cover slip did not lie absolutely flat; air bubbles were caught under it and these were gently squeezed out by slight pressure on the cover slip with a pencil point. When this had been done no typical ova were to be seen. A cover slip was then placed
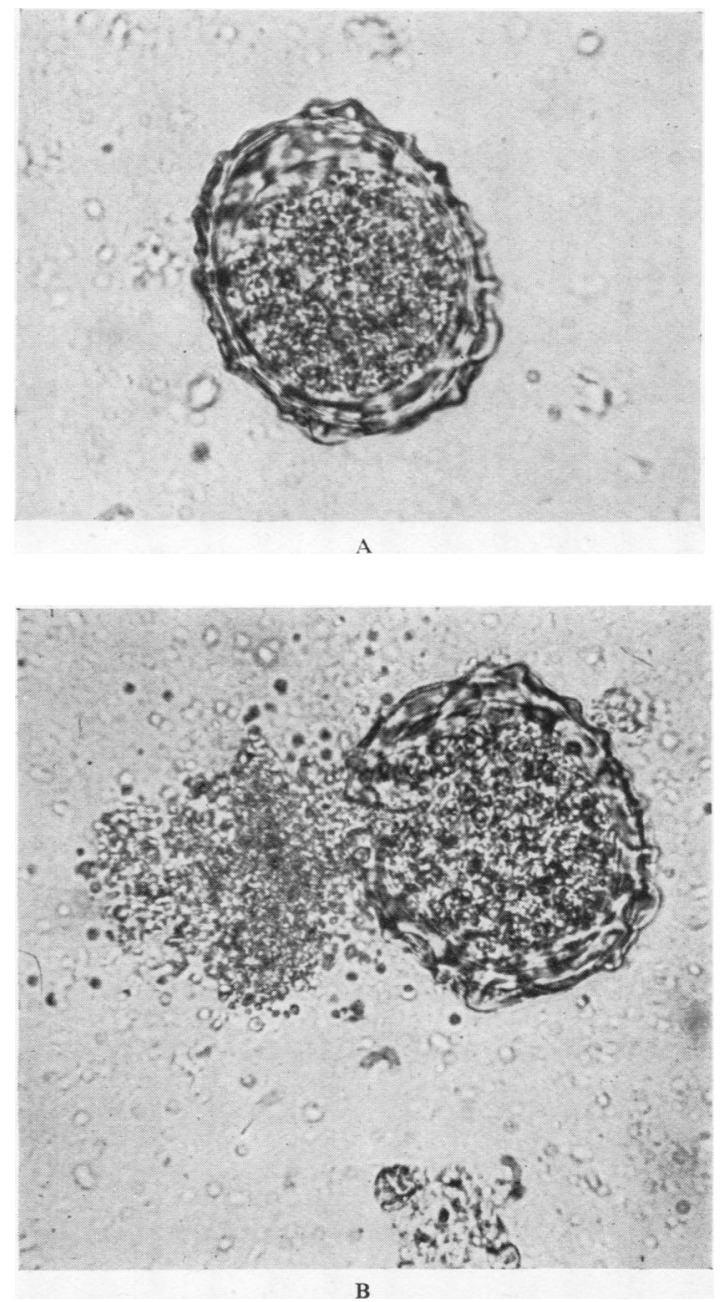

gently on another drop of the faecal emulsion. Under the 1 in. objective a typical ovum was moved to the centre of the field, and, while the ovum was observed, light pressure was exerted 


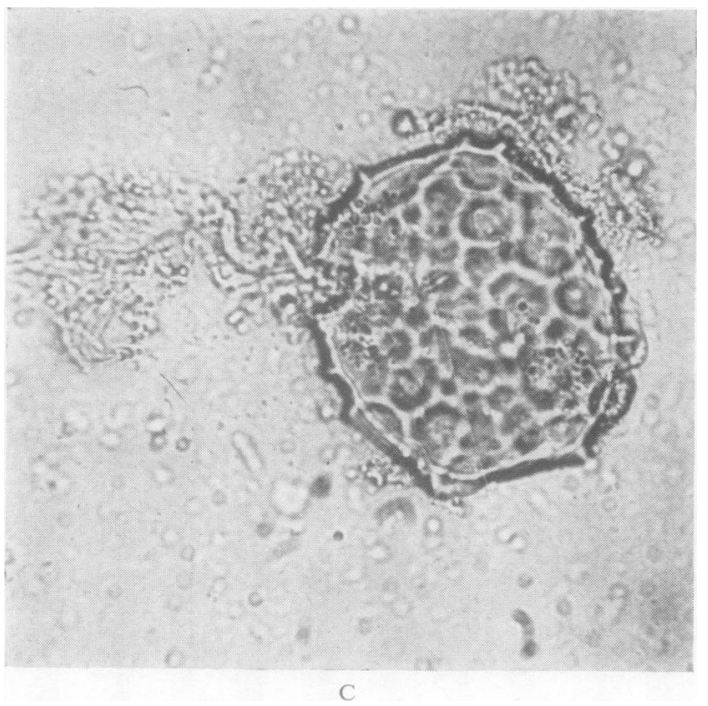

with a pencil point. The ovum was seen to burst, the granular contents flowed out, and the general appearance was completely altered when the pressure was released. The photographs illustrate the changes that occur: $\mathrm{A}$ is the untouched ova, B after very light pressure, and $\mathrm{C}$ after the slightly greater pressure that is usually exerted to make the cover slip lie flat.

This observation may explain why some ascaris ova are difficult to recognize, and it would be best when looking for these ova to make a conscious effort to avoid exerting any pressure on the cover slip.

I should like to thank $\mathrm{Mr}$. J. G. Williamson, the photographer to the Birmingham Children's Hospital. for his co-operation and excellent photographs.

\section{REFERENCE}

Todd, J. C., and Sanford, A. H. (1948). Clinical Diagnosis by Laboratory Methods, 11 th ed. London.

\section{SCHOLARSHIPS IN AID OF SCIENTIFIC RESEARCH}

The Council of the British Medical Association is prepared to receive applications for Research Scholarships, as follows:

An Ernest Hart Memorial Scholarship, of the value of $£ 250$.

A Walter Dixon Scholarship, of the value of $£ 250$.

One or More Research Scholarships, each of the value of $£ 200$.

These scholarships are given to candidates whom the Science Committee of the Association recommends as qualified to undertake research in any subject (including State medicine) relating to the causation, prevention, or treatment of disease.

In addition, applications are invited for the award of the following research scholarship:

The Insole Scholarship, of the value of $£ 250$, for research into the causes and cure of venereal disease.
Each scholarship is tenable for one year, beginnin on October 1, 1953. A scholar may be reappointed for not more than two additional terms. A scholar is not necessarily required to devote the whole of his or her time to the work of research, but may be a member of H.M. Forces or may hold a junior appointment at a university, medical school, or hospital, provided the duties of such appointment will not. in the opinion of the Science Committee, interfere with his or her work as a scholar.

Applications for scholarships must be made not later than March 31, 1953, on the prescribed form. a copy of which will be supplied on application to the Secretary, British Medical Association, B.M.A. House, Tavistock Square, London. W.C.1.

Applicants are required to furnish the names of three referees who are competent to speak as to their capacity for the research contemplated. 